\title{
OBSERVATIONS ON THE WEBS AND LIFE HISTORY OF HOMALOMETA NIGRITARSIS (ARANEAE: TETRAGNATHIDAE): A SPIDER THAT LAYS ITS EGGS IN ROWS
}

\author{
By RoBERT L. EDWARDS ${ }^{1}$ and ANNABEL D. EDWARDS ${ }^{2}$ \\ ${ }^{1}$ Box 505, Woods Hole, MA 02543 U.S.A. \\ ${ }^{2}$ Massachusetts General Hospital, Department of Anesthesia, \\ WACC Suite 324, Boston, MA 02114 U.S.A.
}

\begin{abstract}
The small (2.5-3.0 mm), colorful metine spider, Homalometa nigritarsis Simon 1897, Family Tetragnathidae, has previously been reported from northern Mexico, Panama and the southern islands of the Lesser Antilles (Levi 1986). In the rain forest of northeastern Puerto Rico it is most frequently found with webbing on the larger outer concave surfaces of pendulous leaves. $H$. nigritarsis typically makes a circular, relatively flat retreat within which the female deposits two parallel rows of naked eggs. The rows are produced at intervals; as one row hatches another replaces it shortly thereafter. Evidence of up to four generations of rows has been observed. Above the retreat, and closely aligned with it, the spider builds a nearly invisible, delicate orb web, typically from edge to edge of the leaf (Fig. 1a and b). While retaining the traditional orb-web, $H$. nigritarsis has adopted a unique habitat and set of life history features.
\end{abstract}

\section{Materials AND Methods}

\section{Habitat}

The observations on Homalometa nigritarsis reported here were all made in the immediate vicinity of the El Verde Field Station of the University of Puerto Rico, at elevations between 250 to $320 \mathrm{~m}$, in the rain forest of El Junque, Luquillo Province, Puerto Rico. The first example of webbing was found on the under side of the leaf of a cultivar of Hibiscus in February 1994. It was a well constructed, roughly circular retreat, $30 \mathrm{~mm}$ in diameter, within which were two parallel

Manuscript received 28 April 1998. 
rows of eight evenly spaced eggs without an attending spider. The retreat was similar to those produced by Clubiona but the disposition of the eggs was clearly unusual. In December 1995, many immature specimens and adult females were collected when sweeping the canopy of guamá, Inga laurina (Sw.), at approximately $15 \mathrm{~m}$ above ground. At the same time and at about the same height, a second female in a retreat with similar rows of eggs was found on the underside of the tip of a leaflet of the sierra palm, Prestoea montana (R. Grah.). Suggestive remnants of an orb were present. Further intensive searches during that trip and two subsequent trips in December 1996 and February 1997 resulted in no further specimens being found. While nightlighting in September 1997, we discovered a third specimen with a retreat and, on close examination, an orb web on the upper surface of a pendulous leaf of guamá. We changed our search image and began to inspect the outer surfaces of pendulous leaves for the circular, more obvious retreats. This resulted in finding fairly large numbers of specimens with orbs within a short period of time and without difficulty. The spiders occurred most frequently on the longer, concave leaves of trees like the mango (Mangifera indica L.), less often on two species of Inga, gaumá and guaba (I. vera, Willd.), and laurel geo [Ocotea leucoxylon (Sw.)]. A few specimens were found on other species of trees with broader leaves which were not so pendulous but did have concave upper surfaces. These scarcer finds occurred on orange (Citrus aurantium $\mathrm{L}$ ), cafe silvestre (Casearia silvestris Sw.), and even one spider with webbing in a rounded vertical recess on the leaf of a cultivar of banana (Musa). The common and scientific names of the trees used above are those provided in Little and Wadsworth (1989).

The optimal search image involved looking for a circular retreat on the upper surface of leaves as described above. The orb web itself is not normally visible unless viewed along the plane of the orb, and even then is seen only with difficulty. The retreats of older instars and especially adult females were usually heavily invested with silk and often visible even from several meters away. The spiders were usually aggregated (five to twelve or more individuals including adult females) on single trees in an area a few meters square. Few solitary individuals were found. Adult females and immature spiders have been taken in February, May, October, and December. Identifying the spider was troublesome and eventually solved, thanks to Dr. Herbert Levi. 
The spider

Females average $2.7(2.5-3.0) \mathrm{mm}$ in total length and males 2.5 $\mathrm{mm}$. Live specimens of both sexes have a lustrous olive green cephalothorax, with a ragged jet black marginal line and submarginal black triangular spots along radial lines. The sternum and legs are a paler green with the distal end of each tarsus marked with black. About $50 \%$ of the dorsal surface of the abdomen is a shiny, brown oval area, surrounded by a granular, cream-colored band. The venter is light green with some white spots. When the spider is situated dorsal side down under the orb, its green color provides good camouflage. Laterally, the abdomen is distinctively three tiered, brown, cream and green. With the exception of black tarsi, preserved specimens quickly lose their color and end up generally yellowish overall. Morphologically the spider is not an obvious member of the Family Tetragnathidae, without unique spines or trichobothria, elongated chelicera in the males, or features of the palp that would direct one's immediate attention. The fertilized female, however, sports a striking feature. The embolic cap of the male, a darkly colored horn-like structure, remains firmly attached in the fertilization ducts of the female. When both caps are present, they give the appearance of clasping horns on either side of the simple bulbous swelling of the epigynum.

\section{Collection of material and measurements of web features}

Spiders with webs were usually found on leaves at the outer ends of branches in open areas exposed to sunlight or bright light much of the day. They were found from 2 to $15+\mathrm{m}$ above the ground. Once located, leaves with webbing were carefully removed for examination in the laboratory and placed in separate containers. The orb webs were exceedingly delicate and easily damaged or destroyed by disruptions such as removing the leaf for examination, strong winds and heavy rainfall. A proprietary foot powder spray, Desenex ${ }^{\circledR}$, containing talc and aluminum chlorohydrex, was sprayed on the webbing to enhance its visibility (Fig. 1a). The orbs were examined and measured under a stereobinocular microscope with fiber optic light aimed parallel to the plane of the orb. The orb webs overall varied from circular to ellipsoidal, thus the spiral turns were counted along both the vertical and horizontal axes in undamaged sectors. Similarly, both axes of the area 

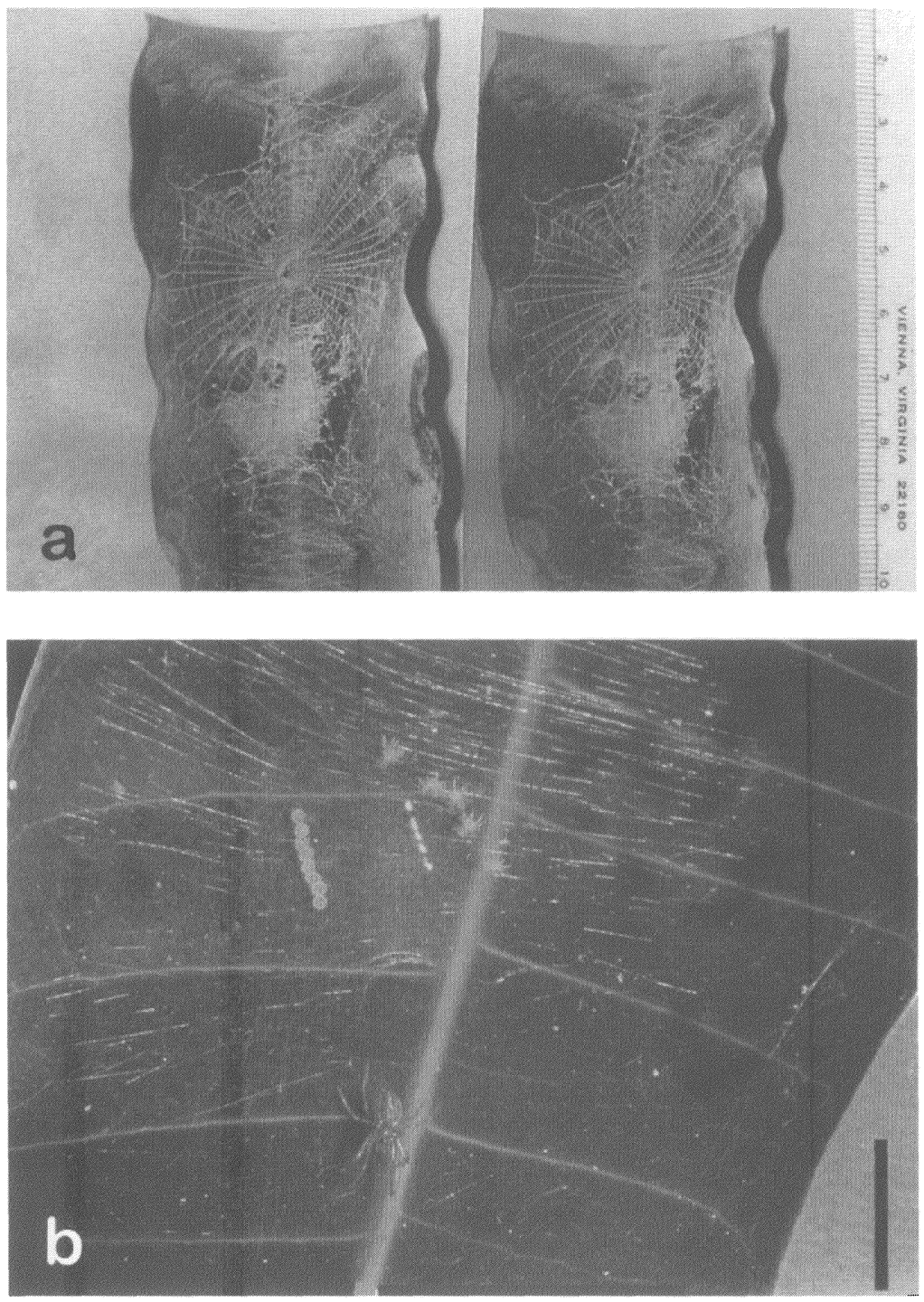
enclosed by the spiral turns (capture area) were measured. The retreats were usually sufficiently invested with silk to be readily seen and measured directly without spraying. Adult spiders were measured to the nearest $0.1 \mathrm{~mm}$ (Table 1). Voucher specimens of the spider and photographs of the webbing have been deposited in the Museum of Comparative Zoology, Harvard University, Cambridge, MA.

\section{The retreat}

The retreat is essentially circular in outline with the diameter averaging $3.2 \mathrm{~cm}$. In newly constructed retreats of older preadult instars there is usually an obvious narrow band of silk stretching across the leaf at roughly right angles to the midrib of the leaf (Fig. 2a). This appears to establish the width of the retreat while maintaining a height of about $4.8 \mathrm{~mm}$ for the center of the retreat from the surface of the leaf. In older retreats that have been more heavily invested with silk overall this band is less obvious. The entrance to the retreat is a sloping archway reinforced with silk and usually adjacent to the midline of the leaf. The retreat entrance is often bordered on one side by the support band of silk (Fig. 2a). Most of the time there is a poorly developed, smaller opening opposite the main entrance, adjacent to and on the upper side of the support band (Fig. 2b). The retreat and its main entrance are located along the central axis of less concave and broader leaves, while on deeply concave leaves, the retreat tends to be to one side of the midrib, which has the effect of reducing the vertical distance of $\pm 5 \mathrm{~mm}$ between the top of the retreat entrance and the hub of the orb. The top of the entrance is connected to the hub of the orb by a converging column of silk serving as a signal line and route to the hub (Figs. 1a and 2c). The spider often sits venter up within the retreat with one of its first legs on the signal line.

Fig. 1. (a) Stereo-pair photographs of the web complex of Homalometa nigritarsis (Simon) on a mango leaf. Webbing sprayed with Desenex ®foot powder. Note the signal line between the retreat and center of the orb. (b) H. nigritarsis female under the hub of the orb-web with eggs and newly hatched spiderlings. Within the retreat is a row of eight eggs on the left and five egg shells on the right. Recently hatched first instar spiderlings soon shed their exuvia where they remain on the upper surface of the retreat. The entrance to the retreat has a faintly defined arch approximately halfway between the spider and the eggs. The webbing is not sprayed with powder. Note that the orb does not show up. Scale bar $=1 \mathrm{~cm}$. 
Table 1. Statistical parameters for webs and life history features. Average spider weight based on least squares equation for fresh weight (ln weight $\mathrm{mg}=-1.874+$ $2.733 \mathrm{ln}$ length $\mathrm{mm}$ ) in Table 3 of Edwards and Gabriel (1998). The average spider weight is for adults found with webs. Total web area based on maximum extent of radials. Capture web area based on area enclosed within well defined spirals.

\begin{tabular}{|c|c|c|c|}
\hline & $\mathbf{n}$ & Mean \pm 2 SD & Range \\
\hline Average spider weight (mg) & 15 & $2.5 \pm 0.7$ & 1.9 to 3.1 \\
\hline \multicolumn{4}{|l|}{ Total web } \\
\hline Length $(\mathrm{cm})$ & 13 & $11.6 \pm 4.7$ & 6.2 to 14.0 \\
\hline Width $(\mathrm{cm})$ & 13 & $5.2 \pm 1.5$ & 4.0 to 6.9 \\
\hline Area $\left(\mathrm{cm}^{2}\right)$ & 13 & $188.9 \pm 100.1$ & 116.9 to 285.9 \\
\hline \multicolumn{4}{|l|}{ Capture web } \\
\hline Length $(\mathrm{cm})$ & 13 & $7.2 \pm 2.9$ & 5.2 to 10.0 \\
\hline Width (cm) & 13 & $4.8 \pm 1.2$ & 4.0 to 6.0 \\
\hline Area $\left(\mathrm{cm}^{2}\right)$ & 13 & $27.4 \pm 12.5$ & 17.3 to 39.3 \\
\hline \multicolumn{4}{|l|}{ Radii } \\
\hline Average length (cm) & 26 & $3.0 \pm 0.8$ & 2.4 to 3.8 \\
\hline Number & 13 & $40.3 \pm 25.0$ & 25.0 to 57.0 \\
\hline Number / total area & 13 & $0.23 \pm 0.16$ & 0.11 to 0.39 \\
\hline Number / capture area & 13 & $1.5 \pm 0.3$ & 0.8 to 2.4 \\
\hline \multicolumn{4}{|l|}{ Spirals } \\
\hline Along vertical axis & 13 & $51.9 \pm 28.4$ & 26.0 to 75.0 \\
\hline Along horizontal axis & 13 & $43.8 \pm 21.3$ & 24.0 to 67.0 \\
\hline Separation of spirals $(\mathrm{mm})$ & 13 & $0.09 \pm 0.06$ & 0.06 to 0.17 \\
\hline Number / total area & 13 & $0.27 \pm 0.15$ & 0.14 to 0.39 \\
\hline Number / capture area & 13 & $1.70 \pm 1.01$ & 0.8 to 2.4 \\
\hline Number radii / number spirals & 13 & $0.89 \pm 0.62$ & 0.5 to 1.6 \\
\hline Height center capture web (mm) & 9 & $10.7 \pm 3.0$ & 9.0 to 13.0 \\
\hline \multicolumn{4}{|l|}{ Retreat } \\
\hline Length (cm) & 20 & $3.4 \pm 1.3$ & 2.5 to 4.5 \\
\hline Width $(\mathrm{cm})$ & 20 & $3.1 \pm 1.6$ & 2.4 to 4.8 \\
\hline Height entrance (mm) & 9 & $4.8 \pm 1.0$ & 4.0 to 5.0 \\
\hline \multicolumn{4}{|l|}{ Number of eggs } \\
\hline Eggs / row & 23 & $11.1 \pm 10.0$ & 4.0 to 29.0 \\
\hline Eggs in 2 rows & 15 & $23.1 \pm 16.7$ & 14.0 to 41.0 \\
\hline Diameter of eggs (mm) & 25 & $0.59 \pm 0.30$ & 0.40 to 0.70 \\
\hline
\end{tabular}

\section{The orb-web}

Web position and shape varies as a function of leaf shape. On longer leaves, like those of mango, the webbing tends to be located on the distal third of the leaf. On shorter leaves (Ocotea and Inga), the webbing occupies the lower half of the leaf. On broader ovate leaves with a width greater than $5 \mathrm{~cm}$, the orb is usually centrally located and 
more circular in outline (Fig. 1a). On narrower leaves $5 \mathrm{~cm}$ or less, the orb is ellipsoidal with one third to one half of the capture area (radii and spiral turns) extending to the leaf edge. The overall structure of the orb averages $11.6 \mathrm{~cm}$ long by $5.2 \mathrm{~cm}$ wide. The area occupied by the sticky spiral (capture area) averages $7.2 \mathrm{~cm}$ long by $4.8 \mathrm{~cm}$ wide (Table 1). The average number of spiral turns is 51.9 (26 to 75$)$ along the long axis, as opposed to 43.8 (24 to 67) along its shortest. The hub is an irregular mesh with a hole through which the spider moves onto the upper surface. Immediately surrounding the hub is a small number of relatively closely spaced turns with the spacing of the turns following almost to the perimeter averaging $\pm 1 \mathrm{~mm}$. The outer few turns on the long axis become increasingly wider and irregular. The hub averages $10.7 \mathrm{~mm}$ above the surface of the leaf. These heights are maintained from the leaf surface whether the entrance to the retreat is directly beneath the hub or offset to one side. The bridge line of the orb is usually irregularly defined and most often anchored by several additional radial support threads fastened along the edge of the leaf and on the leaf surface. Overall the radii numbered from 24 to 57 with an average of 40.3. No spider younger than the antepenultimate instar was found with an orb.

\section{Eggs}

The rows of eggs were placed parallel to the sides of the central corridor of the retreat and were individually suspended between the leaf surface and the roof of the retreat. The number of eggs in a row averaged 11.1 (4 to 28). In those cases where there were two rows of eggs, one row was clearly produced earlier than the other. In one retreat with two rows of eggs, following the hatching of one of the rows, a new row replaced the original row within two days (Fig. 1b). The eggs varied in size from 0.4 to $0.7 \mathrm{~mm}$, averaging $0.59 \mathrm{~mm}$ (Table 1). Retreats of 20 fertilized females variously had no eggs (10\%), one row of eggs (30\%), and the rest had two rows of eggs, or two rows of eggs with the exuvia of other earlier sets of eggs scattered about on the upper surface of the retreat adjacent to the original row. In one instance with two rows of eggs, there were two additional rows of the remains of egg cases, suggesting that it was possible for these spiders to have up to four sets of eggs. In all 3 cases where the females were fertilized on one side only (as determined by seeing only one male embolic cap in place), only one row of eggs was found, never two. First instar spiderlings varied from 0.8 to $1.1 \mathrm{~mm}$, averaging $0.95 \mathrm{~mm}$. 

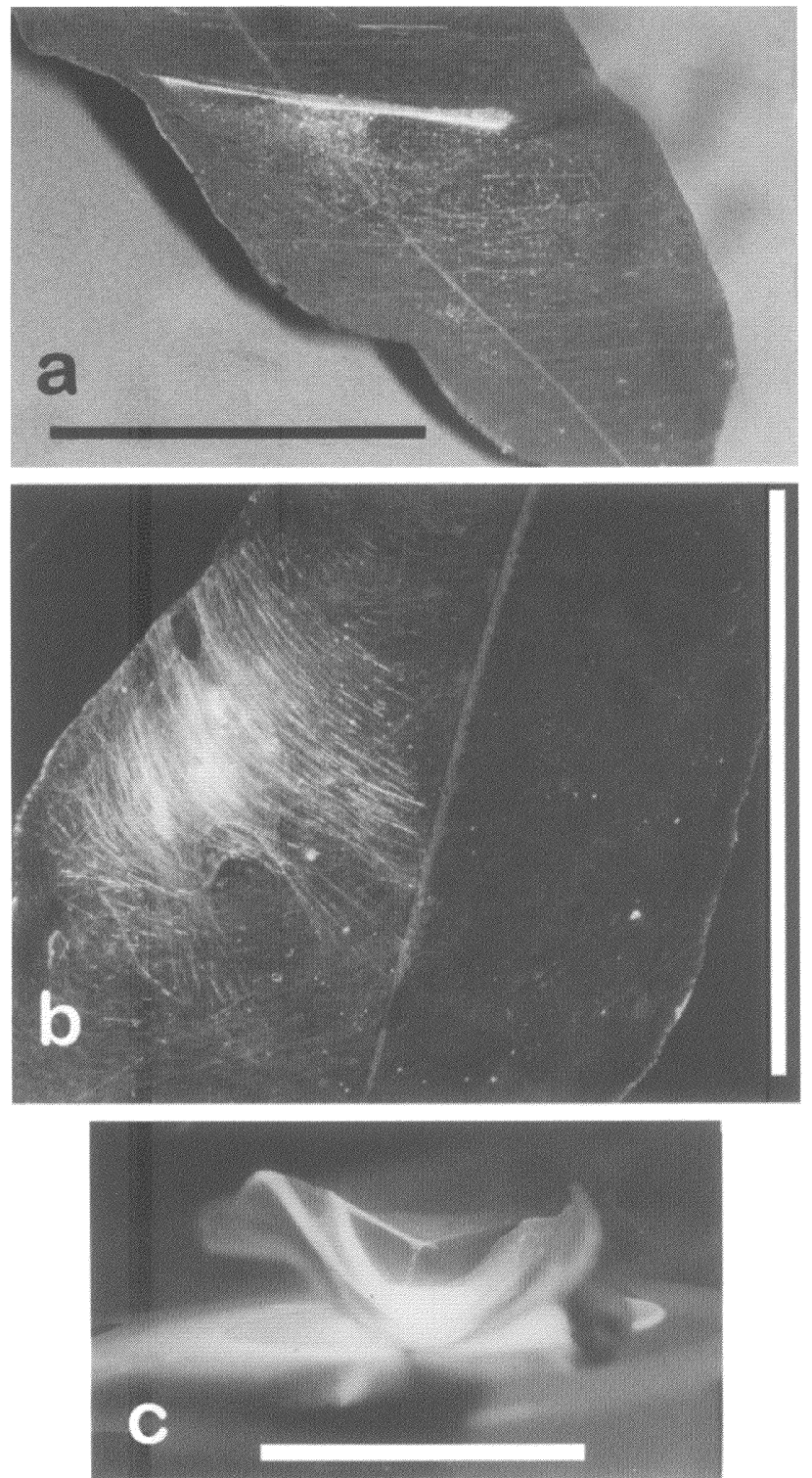


\section{Food and feeding}

Twelve leaves with undamaged orb webs containing spiders were pinned to tree trunks and observed intermittently day and night for the particular purpose of determining behavior and prey captured in the orb by the spider. The orb-webs were never replaced regularly and there was little evidence of repair activity after minor damage. The spiders could be found almost anywhere in the webbing at any time, day or night, but were most frequently observed in the retreat with one leg reaching out touching the signal line. No prey or remnants thereof were found in the webbing when first collected. In one case at night, a very small whitefly, $\pm 1 \mathrm{~mm}$, landed on the outer edge of the orb. It was immediately detected by the spider from within the retreat, retrieved and carried back to the retreat almost instantaneously; too quickly, in fact, to get a close look at the fly. Other flies, about the size of laboratory fruit flies, had been captured in other orbs and the spiders were observed feeding on them from beneath the orb. They were not wrapped. A small beetle $( \pm 0.5 \mathrm{~mm})$ trapped near the outer edge of the capture area was cautiously approached and deliberately ejected from the web by the spider with a flick of its foreleg. Small cockroaches (3 to $4 \mathrm{~mm}$ ) were observed frequenting the retreats and were seemingly tolerated by the spider.

\section{Attempts to raise spiders}

While still in Puerto Rico we removed a number of late instar spiders from webs and brought them home. Several third instar spiderlings $( \pm 1.2 \mathrm{~mm})$ produced a minimum of random webbing on the side of the jar. These were provided with Drosophila which were larger than the spiderlings in size. Although the flies became entangled in the webbing, they were not observed to be fed upon by the spiders and the spiders soon died. An antepenultimate male produced a thin retreat and a

Fig. 2. (a) The obvious band of silk seen when older instar spiders begin to develop a permanent site. The entrance to the retreat is below the band on the right hand side. Not sprayed with powder. The orb is in place but is virtually invisible even to the camera. Scale bar $=3 \mathrm{~cm}$. (b) The retreat of an older adult female on a deeply concave citrus leaf. Not clearly visible within the retreat are nine recently deposited eggs on the lefthand side and five soon to hatch on the right. Usually the more deeply concave the leaf, the more the retreat is positioned to one side of the mid-rib of the leaf. Note secondary retreat entrance diametrically opposite the main entrance. Not sprayed with powder. Scale bar $=5 \mathrm{~cm}$. (c) End-on view of the webbing illuminated with fiber optic light parallel to the plane of the orb. Note the signal line between the entrance of the retreat and the hub of the orb. On leaf of mango. Not sprayed with powder. Scale bar $=5 \mathrm{~cm}$. 
poorly constructed orb. It shed within five days and twelve days later it matured. A penultimate male $( \pm 2.4 \mathrm{~mm})$ also constructed a thin, ill defined retreat. Three days later it matured. We did not directly observe these latter two spiders feeding on Drosophila although the flies appeared to have been fed upon. In a further experiment a leaf with five eggs, a female, and one early instar spider $( \pm 1 \mathrm{~mm})$ was placed in a glass jar with a layer of damp sand in the bottom to maintain the humidity. In this case, greenhouse whiteflies, aphids and Drosophila were introduced as food. Two of the eggs hatched within days and the second instar spiderlings had produced barely visible retreats on the side of the jar several days later. After twenty days these spiders had approached a length of about $2 \mathrm{~mm}$, still without significant enhancement of their retreats and with some additional longer, randomly located single threads in the immediate vicinity. The original early instar spider had reached a length of approximately $2.3 \mathrm{~mm}$ by the 28th day, still without a clearly defined retreat. All these spiders died before they reached maturity.

\section{EFFECT OF HURRICANE GEORGES}

Hurricanes Georges, a Category 3 hurricane with winds of 115 mph hit Puerto Rico on the evening of 21 September 1998, traveling east to west approximately bisecting the island. The El Verde Field Station and El Junque were just to the north of the storm path. We arrived on the 10th of October. Almost all of the planned research had to be canceled due to the devastation of habitats and limited research facilities. Except for a few sheltered areas, the forest was defoliated. It was possible, however, to examine the effect of Georges on the distribution and abundance of $H$. nigritarsis.

In a few trees (Ocotea) in a sheltered area that had escaped extreme defoliation and where previously aggregations of $H$. nigritarsis had been observed, a few solitary individuals were found higher up $( \pm 10 \mathrm{~m})$. A small aggregation (5+) about $15 \mathrm{~m}$ above ground was noted in a single tree (Ocotea) that had escaped serious damage. In marked contrast to earlier trips, however, $H$. nigritarsis occurred sporadically over a considerable area on a wide variety of species of vines, forbs and other understory plants with larger leaves from 1 to $3 \mathrm{~m}$ above ground. These were usually solitary individuals and mostly early instars. 


\section{DISCUSSION AND SUMMARY}

Homalometa nigritarsis has adopted an unusual habitat for a member of the Family Tetragnathidae. It has combined its orb-web with a closely aligned retreat on the upper surface of a single leaf. The distance between the entrance of the retreat, the surface of the leaf and the center of the orb appears to be carefully maintained. The eggs are deposited separately in two rows, suspended between the surface of the retreat and the surface of the leaf. The rows of eggs are spaced in time, with each succeeding row being deposited after the other hatches. Spiderlings molt shortly after hatching on the surface of the retreat adjacent to the position of the eggs, and disperse a day or two later.

Craig (1987a), has suggested that orb-web spiders show an evolutionary trend to a smaller size as they diversify and find new habitats and resources, with a tendency to develop web architecture other than orbs. This small spider has maintained the orb-web architecture but has found a new and unusual habitat which we suggest optimizes new resources, i.e., small prey hovering around and/or intending to land on the surface of leaves. The ratio of radii to spiral turns is less than one, and the narrow spacing of the spiral turns indicates a low energy orb adapted for small, weaker prey such as the flies we observed (Craig 1987a). The various statistical parameters for the web are similar to those of Leucauge globosa (O.- Pickard- Cambridge), a comparably small tetragnathid (cf. Table 2, Opell 1997, based on data given in Craig 1987a,b).

The embolic caps of known Homalometa species are certainly unusual for a tetragnathid, a feature more often found in the Araneidae. This presumably enhances the primacy of the first mating. The relatively few eggs produced by Homalometa suggest a low natural mortality. We noticed that the abundant anoles (several species) seem to pay no attention to the webs and the spiders within. In sum, this spider has evolved to fit an unusual habitat and developed a number of other life history features that make it unique without abandoning the classical orb-web.

\section{ACKNOWLEDGMENTS}

Dr. Herbert W. Levi, Museum of Comparative Zoology, Harvard University, Cambridge, kindly identified the spider. Various individuals 
associated with the El Verde Field Station have been helpful in many ways in facilitating our study, including, among others, Dr. Jill Thompson and Mrs. Hilda Lugo. Ms. Maria Aponte assisted with the identification of trees. Dr. Barbara Richardson, Napier University, Edinburgh, Scotland, suggested the use of foot powder spray to help make the webbing easier to see. Dr. Robbert Créton, Marine Biological Laboratory, Woods Hole kindly provided Drosophila cultures. Of the photographs, figures 1a and b were made by Eric Edwards, and figures 2a, $\mathrm{b}$, and c by Annabel Edwards. Catherine Craig, Museum of Comparative Zoology, Harvard University, kindly critiqued the manuscript and made many helpful suggestions, as did the anonymous reviewers.

\section{Literatue Cited}

Craig, C. L. 1987a. The significance of spider size to the diversification of spider web architectures and spider reproductive modes. American Nat. 129: 47-68.

Craig, C. L. 1987b. The ecological and evolutionary interdependence between web architecture and web silk spun by orb web weaving spiders. Biol. J. Linn. Soc. 30: 135-162.

Edwards, R. L. and W. L. Gabriel. 1998. Dry weight of fresh and preserved spiders (Araneida: Labidognatha). Ent. News 109(1): 66-74.

Little, Jr., E. L. and F. H. Wadsworth. 1989. CommonTrees of Puerto Rico and the Virgin Islands (Agricultural Handbook No. 249, 2nd printing). Washington, DC: U.S. Dept. Agriculture, Forest Service.

Levi, H. W. 1986. The Neotropical orb-weaver genera Chrysometa and Homalometa (Araneae: Tetragnathidae). Bull. Mus. Comp. Zool. Harv. 151: 91-215.

Opell, D. B. 1997. A comparison of capture thread and architectural features of Deinopoid and Araneoid orb-webs. J. Arachnol. 25: 295-306. 

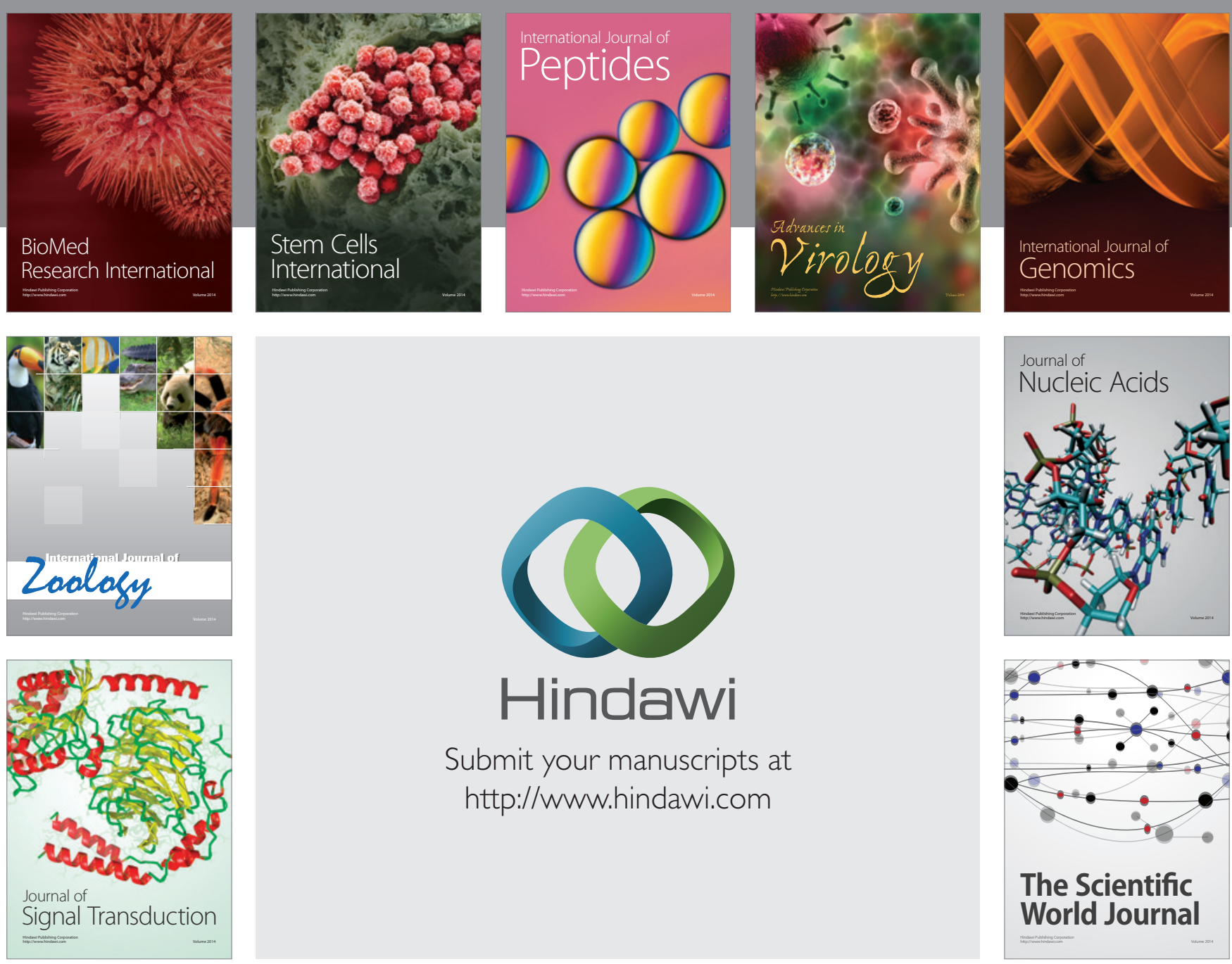

Submit your manuscripts at

http://www.hindawi.com
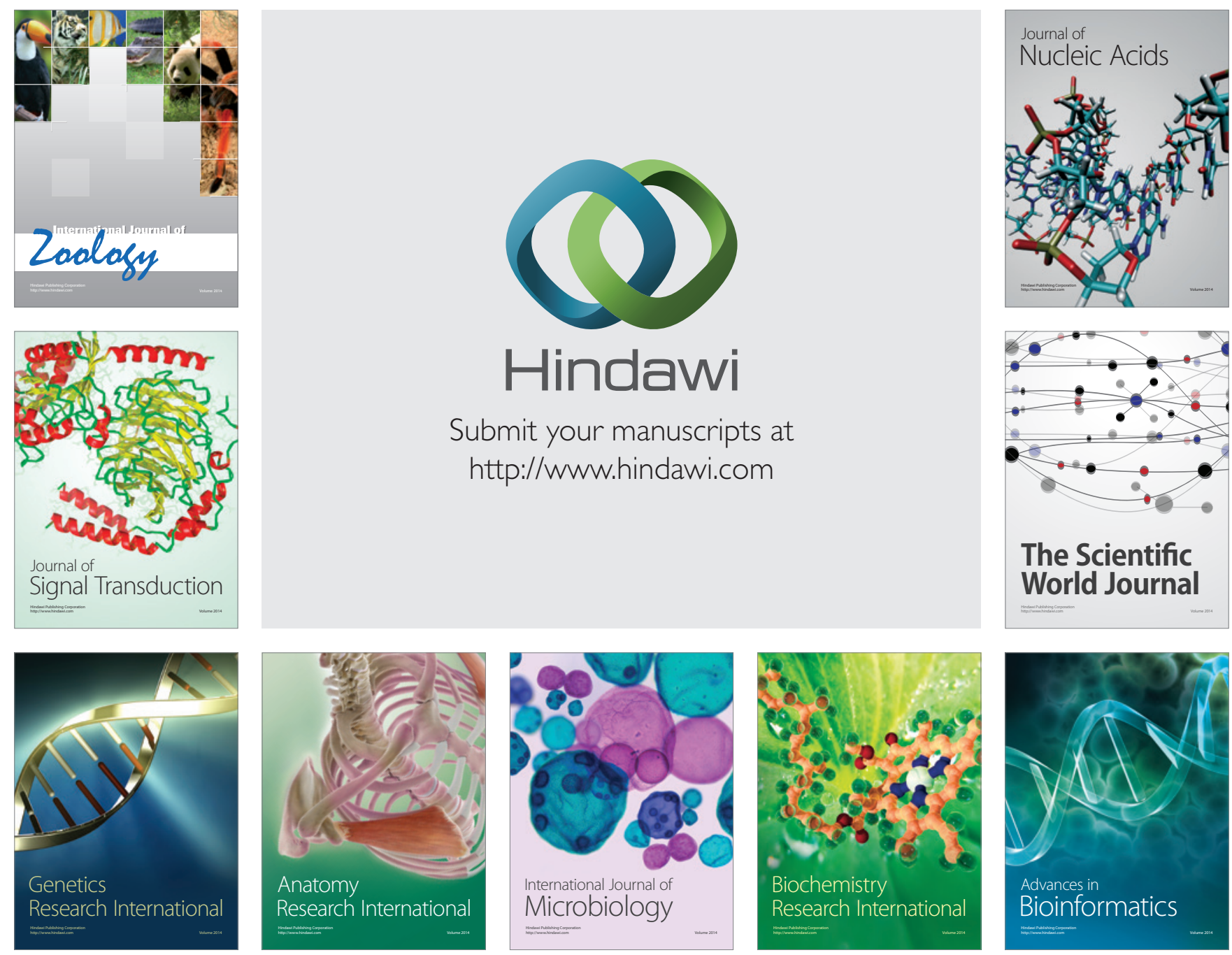

The Scientific World Journal
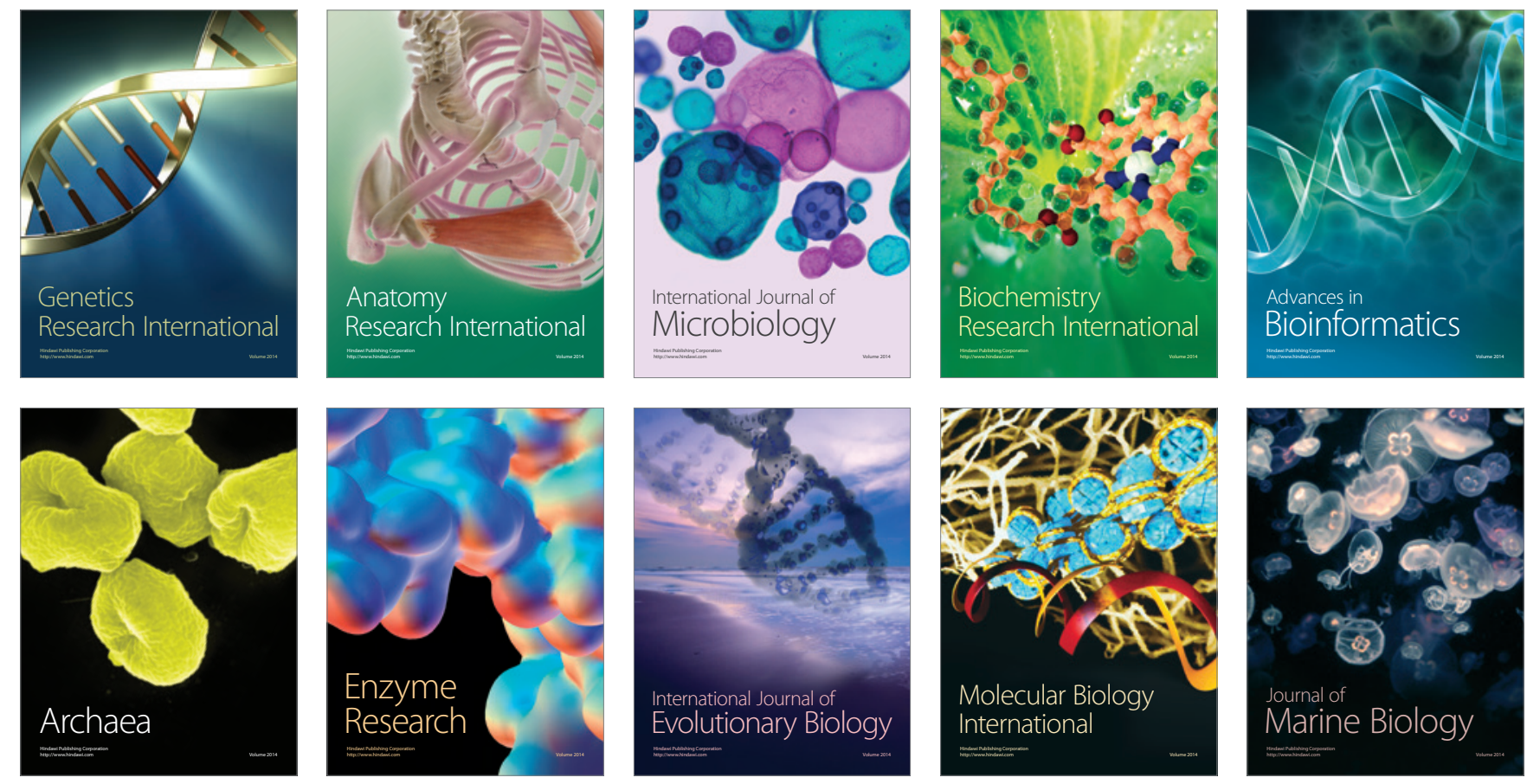